\title{
Using airborne laser scanning data for detecting canopy gaps and their understory type in mature boreal forest
}

\author{
Mikko Vehmas • Petteri Packalén • Matti Maltamo • \\ Kalle Eerikäinen
}

Received: 30 March 2010 /Accepted: 3 January 2011 /Published online: 10 June 2011

(C) INRA and Springer Science+Business Media B.V. 2011

\begin{abstract}
- Introduction Canopy gap dynamics in old-growth boreal forests is a result of tree mortality caused by insects, diseases, or meteorological phenomena. Canopy gaps improve the possibilities of natural regeneration, and concentrations of decomposed deadwood are often found in these natural openings, which provide specific habitats for many deadwood-dependent species and organisms.

- Methods Detailed monitoring setups for canopy gaps have been difficult to organize because of the expense of conventional field inventory techniques. Using threedimensional airborne laser scanning (ALS), canopy gaps can be detected and analyzed even over large sample areas. - Results In this study, we show how differences between the canopy gaps of seminatural and managed forests can be determined and how canopy gaps can be categorized using ALS data because the ALS characteristics reflect the variation of vertical structure due to different vegetation or deadwood layers in the canopy gaps.

- Conclusion The study show promising results on the applicability of ALS data for the automatic identification of canopy gap types and detection of indirect indicator characteristics usable for assessing the naturalness of boreal forests. Moreover, our method bases on the vertical distribution of laser pulses characterizing the vegetation layer, and it can therefore be applied to other vegetation zones where the ALS is applicable.
\end{abstract}

\section{Handling Editor: Barry Gardiner}

M. Vehmas $(\bowtie) \cdot$ P. Packalén $\cdot$ M. Maltamo

Faculty of Science and Forestry, University of Eastern Finland,

Yliopistokatu 2, FI-80100, Finland

e-mail: mikko.vehmas@uef.fi

K. Eerikäinen

Joensuu Research Unit, Finnish Forest Research Institute,

Yliopistokatu 6, 80100 Joensuu, Finland
Keywords Coarse woody debris - Lidar - Managed forest . Remote sensing $\cdot$ Seminatural forest

\section{Introduction}

In undisturbed old-growth (natural) boreal forests, the regeneration dynamics is mainly sustained by small-scale canopy gap disturbances (Kuuluvainen 1994). In oldgrowth forests, canopy gaps are formed by dying individual trees or tree cohorts and provide ecologically important habitats for many endangered or threatened species that have specialized on feeding on decomposing coarse woody debris (CWD) (e.g., Siitonen et al. 2000). In most cases, the death of individual trees is caused by wind or snow destruction, different diseases, or insects (e.g., Kuuluvainen 1994; Liu and Hytteborn 1991; McCarthy 2001). Multilayer forests are formed from forest stand scale, regular disturbances which promote regeneration in natural canopy openings.

Canopy gaps also exist in managed forests, but most openings originate from harvestings and other logging activities. Large or even medium diameter CWD is generally missing from these man-made openings. However, some regeneration can be found in the canopy gaps in managed forest stands (e.g., Zhu et al. 2003).

The theory of canopy gap dynamics in boreal forests has already been well studied, and its importance to forest ecology is shown by, for example, Liu and Hytteborn (1991) and McCarthy (2001). However, more detailed analyses of canopy gap properties are lacking due to difficulties in the delineation of gap areas and the shortage of cost-efficient methods needed for the collection of data in the field. Airborne laser scanning (ALS), however, provides spatially accurate three-dimensional (3D) information on targets. Therefore, it is a potential method to 
replace conventional field inventory techniques for determining forest stand characteristics, vertical structure attributes, natural regeneration, and different measures of deadwood (e.g., Bollandsås et al. 2008; Maltamo et al. 2005; Pesonen et al. 2008).

ALS technology is capable of defining canopy gaps where boundaries are formed by the areas exactly underneath the outer circumferences of the tree branches, i.e., canopy drip lines, from 3D point data which contain spatially exact horizontal and vertical information (Ackermann 1999). However, there is no universal definition for the canopy gaps and, therefore, the delineation of the borders and sizes of the canopy gaps vary from one application to another. In their studies, Koukoulas and Blackburn $(2004,2005)$ used a canopy height model (CHM) and a fixed threshold of $4 \mathrm{~m}$ to delineate canopy gaps. On the other hand, Hirata et al. (2008) used three fixed height thresholds (5, 10, and $15 \mathrm{~m}$ ) with the minimum canopy size of $1 \mathrm{~m}^{2}$, where over half of the canopy gaps were less than $5 \mathrm{~m}^{2}$ in size. The minimum sizes of $5 \mathrm{~m}^{2}$ with the height threshold of $5 \mathrm{~m}$ were applied by St-Onge and Vepakomma (2004) and Vepakomma et al. (2008) in their studies on the canopy gap delineation. Zhang (2008) applied a completely different, morphological canopy gap delineation method to mangrove forests and found it to be more flexible and adaptable for vertically variable forests when compared to a fixed height threshold-based delineation. In the study by Gaulton and Malthus (2010) on managed forests, the maximum overall accuracy of $88 \%$, obtained by using high point density data, was achieved for a canopy gap delineation method based on local maxima identification, and filtering and clustering of the laser point clouds with the minimum gap size of $5 \mathrm{~m}^{2}$.

The use of ALS for the determination of canopy disturbance regimes has already been studied by St-Onge and Vepakomma (2004), Koukoulas and Blackburn (2004), and Vepakomma et al. (2008). Describing changes in the canopy gaps, multitemporal ALS data were also used to identify canopy gap dynamics, i.e., appearance, enlargement, reduction, and disappearance of canopy gaps (Hirata et al. 2008; St-Onge and Vepakomma 2004; Vepakomma et al. 2008). In these studies, time series ALS data were analyzed with various subtracting methods. Spatial canopy gap characteristics have been calculated by Koukoulas and Blackburn (2004, 2005) and Zhang (2008), but in their studies based on nontemporal (i.e., cross-sectional) data, the canopy gap dynamics was not taken into consideration. It is also worth mentioning that Vehmas et al. (2009b) recently succeeded in distinguishing canopy gaps according to deadwood, understory vegetation, and clear space by using height distributions of different echoes. The results of their study can be utilized in analyzing the level of naturalness of the boreal forests that are characterized by the amount of CWD.
The aim of this study was to find out differences between canopy gaps measured from seminatural (for terminology, see Rouvinen and Kouki 2008) forests and managed forests. In addition, the identification of canopy gap types and separation based on the existence of seedlings, vegetation, or downed deadwood (DDW) in canopy gaps were of interest. We used two different methods to analyze laser data from canopy gaps: (1) indexes calculated for differences in the size, area, shape, isolation, and diversity of canopy gaps to indicate possible spatial characters of canopy gaps and (2) a novel approach to calculate differences of laser echo heights and intensity values inside the canopy gaps, where the echo height distribution is very low.

\section{Methods}

\subsection{Study area}

The study site is located in the northern part of the Koli National Park $\left(29^{\circ} 50^{\prime}\right.$ E, $\left.63^{\circ} 05^{\prime} \mathrm{N}\right)$ in eastern Finland (Fig. 1). The total area of Koli National Park is about 3,000 ha, where the northern part is about one third of the whole area. The highest hill sites and rocky areas in the northern part have been left unmanaged for at least a hundred years, whereas forest management operations like thinning, clear cutting, and planting were carried out in many forest stands before the establishment of Koli National Park in 1991 (Lyytikäinen 1991; Vehmas et al. 2009a). The area belongs to the continental climate zone and is characterized by a highly variable landscape, with a wide variety of site types, tree species, and slopes with altitudes varying between 95 and $347 \mathrm{~m}$ above sea level.

The study was based on three mature forest landscapes which represented different forest areas within the northern part of the National Park. Two of them were located in managed forests (Fig. 1), and the selection was based on the compartment-wise inventory data. Managed landscapes are thinned, 70-year-old planted spruce (Picea abies L.) forests covering 4.8 and 3.4 ha. The selection of a natural forest landscape of 6.3 ha, with a highly variable mixture of Scandinavian boreal tree species with a great diversity of ages of single tree individuals, was based on the historical inventory data analyzed by Vehmas et al. (2009a).

The field inventory of canopy gaps was implemented in the summer of 2008. The field inventory was guided by smallscale canopy gap maps which were derived from the ALS data. The total number of canopy gaps in the three landscapes was 589. The natural stage forest landscape had 220, and the two managed forest landscapes had 369. All canopy gaps within the three landscape areas were visited, and the characteristics were assessed or measured by using six predefined nonmutually exclusive classes: (1) man-made 
Fig. 1 Map of the northern part of Koli National Park in eastern Finland, with locations of the study sites assigned to the natural forest and managed forests. Forest vegetation zones after Kalela (1970, in Kalliola 1973): South Finland ( 1 hemiboreal and 2 southern boreal), Pohjanmaa-Kainuu (3 middle boreal), and Peräpohjola and Metsä-Lappi (4 northern boreal)

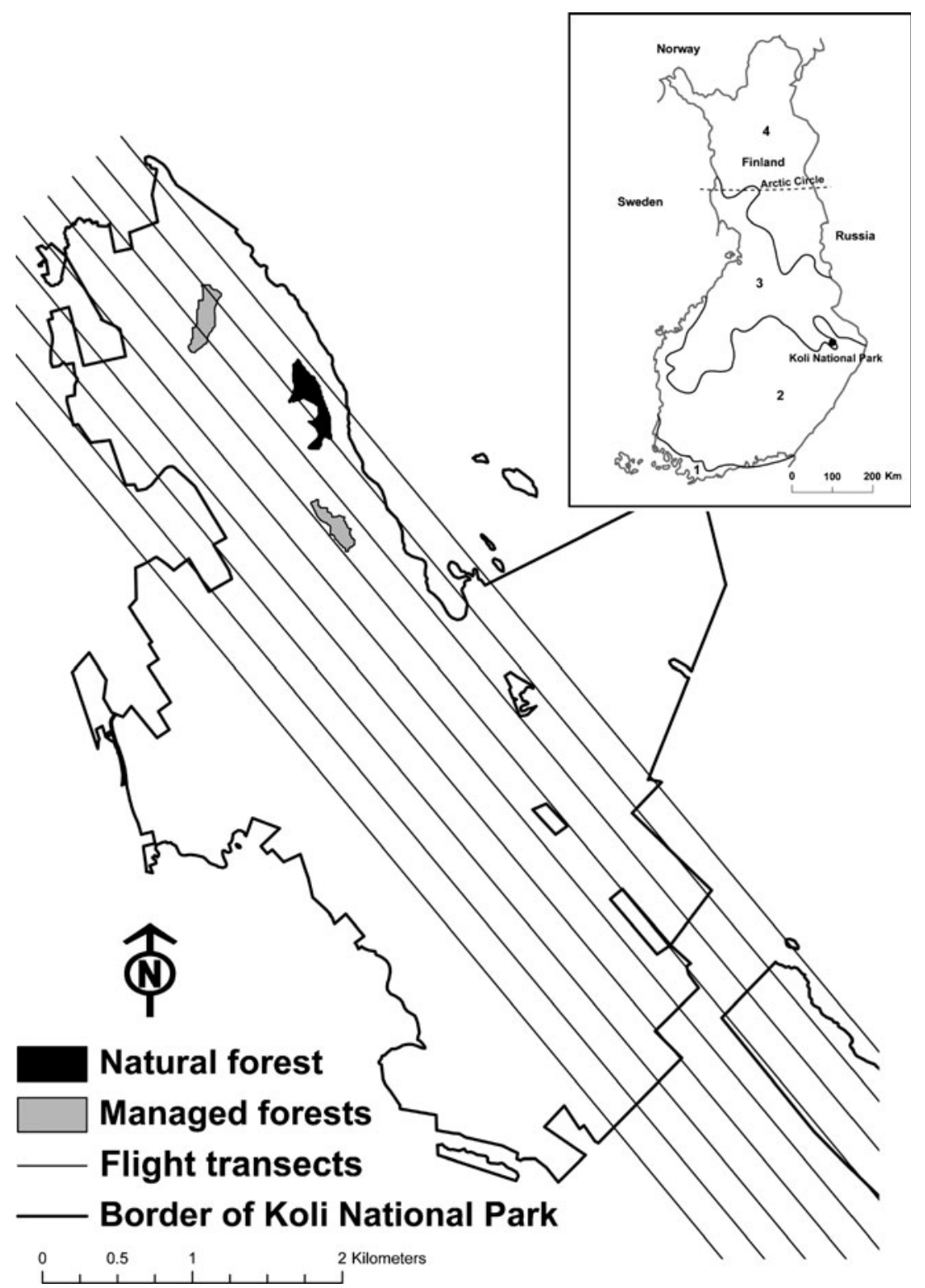

canopy gap (thinning applied), (2) seedlings from 0.3 to $1.3 \mathrm{~m}$ tall, (3) seedlings over $1.3 \mathrm{~m}$ tall, (4) depth of downed deadwood under $0.3 \mathrm{~m}$, (5) depth of downed deadwood over $0.3 \mathrm{~m}$, and (6) dense lesser vegetation (species of nontimber value covering large parts of the canopy gaps). The time difference between the field inventory and scanning of ALS data, which was two growing seasons, was taken into account when making the assessments, for instance, by reducing the heights of the seedlings by an estimate of the expected increment from two growing seasons.

\subsection{Airborne laser scanner data}

The scanning was performed on 13 July 2005, using an Optech ALTM 3100 laser scanner. A total of nine transects (Fig. 1) were flown at an altitude of $900 \mathrm{~m}$ and a flight speed of $75 \mathrm{~m} / \mathrm{s}$.
The area covered was approximately 2,200 ha. The laser pulse repetition rate was $100 \mathrm{kHz}$, and the scanning frequency of a swath was $70 \mathrm{~Hz}$, at an angle of $\pm 11^{\circ}$. The pulse density of the data was $3.9 / \mathrm{m}^{2}$, but because of a nominal side overlap (35\%) and a variation in the terrain, the actual ground hits varied from approximately 3.2 to $7.8 / \mathrm{m}^{2}$. Each one of the three study areas were under two or three fly transects (Fig. 1). The measured data echoes included EUREF-FIN coordinates $(x$, $y$, and $z$ ), flight line numbers, intensity values, and echo types in four classes, which were (1) "first of many," (2) "intermediate," (3) "last of many," and (4) “only."

\subsection{Canopy gaps and classes}

In order to analyze the ALS data, orthometric heights were subtracted from a digital terrain model (DTM) produced by 
the method proposed by Axelsson (2000) to identify the heights of the aboveground level (a.g.l.). A CHM was created using height hits at a.g.l. by an inverse distance weighted interpolation method with a pixel size of $0.5 \mathrm{~m}$. Gaps were segmented from the CHM by using a height threshold limit of $5 \mathrm{~m}$ and assigning a minimum size to the gaps of $5 \mathrm{~m}^{2}$ (see e.g., Vepakomma et al. 2008). Canopy gap polygons were used to select laser echoes with positive $z$ values from the laser data transects as datasets to this study.

All canopy gaps were divided into five different exclusive canopy gap classes (CG-class) based on the six field inventory classes (Table 1). The purpose of the classification was to create classes which can be identified by using the ALS data. In the first class (DDW), there was only downed deadwood of a depth over $0.3 \mathrm{~m}$ or few gaps with large amounts (covering most of the canopy gaps) of downed deadwood also under the depth of $0.3 \mathrm{~m}$. In the canopy gaps of the second class (VEGE) there were a lot of seedlings in the $0.3-1.3-\mathrm{m}$ height range or over $3 \mathrm{~m}$ in height, or there existed seedlings in both of the height classes. In addition, this class (VEGE) included canopy gaps with dense lesser vegetation. The third class (UNDER) included canopy gaps with both, the seedlings and dense lesser vegetation, and the downed deadwood. The fourth class (NO_UNDER) comprised clear canopy gaps with no seedlings, vegetation, or downed deadwood in other words clear space. In the canopy gaps of the fifth class (OTHER) there were the rest of the canopy gaps containing scattered seedlings or only a few fallen stems which all were categorized into the height class below $0.3 \mathrm{~m}$. The total number of canopy gaps by the CG-classes DDW, VEGE, UNDER, NO_UNDER, and OTHERS were 54, 142, 52, 64 , and 277 , respectively. The landscapes of the three study

Table 1 Five different exclusive CG-classes based on the six field inventory classes

\begin{tabular}{|c|c|c|c|c|c|c|c|c|c|}
\hline & 1 & $2 \mathrm{a}$ & $2 b$ & $3 a$ & $3 b$ & $4 a$ & $4 b$ & 5 & 6 \\
\hline DDW & & & & & & & $x$ & $\times$ & \\
\hline VEGE & & & $\times$ & & $\times$ & & & & $x$ \\
\hline UNDER & & & $x$ & & $x$ & & $x$ & $\times$ & $x$ \\
\hline \multicolumn{9}{|c|}{ NO_UNDER } & \\
\hline OTHER & & $\times$ & & $x$ & & $x$ & & & \\
\hline
\end{tabular}

DDW is gaps with downed deadwood, VEGE is gaps with different vegetation, UNDER is gaps with DDW and VEGE, NO_UNDER is gaps with no DDW and VEGE and OTHERS is gaps with small amount of DDW or some seedlings found in field inventory. Manmade canopy gap is class 1,2 is seedlings from $0.3 \mathrm{~m}$ to $1.3 \mathrm{~m}$ tall, 3 is seedlings over $1.3 \mathrm{~m}$ tall, 4 is depth of downed deadwood under $0.3 \mathrm{~m}, 5$ is depth of downed deadwood over $0.3 \mathrm{~m}$, and 6 is dense lesser vegetation. Insignificant amount of content is marked with a, and in great abundance of content is marked with $\mathrm{b}$ sites and the distribution of classified canopy gaps (five CG-classes) over the study sites, respectively, are visualized in Fig. 2.

\section{Analysis}

\subsection{Indexes and statistical tests}

The basic calculation unit was the canopy gap (PATCH). Both, the spatial characteristic calculations and ALS data analyses of the canopy gaps were applied to landscape- and CG-classes (Table 2). In the case of ALS data, only the echoes that fall within the gaps are included in the landscape, class, or patch level analysis.

The density, shape, isolation, and diversity indexes for canopy gaps were calculated using the FRAGSTATS program (McGarigal et al. 2002). The pixel size of rastertype data was $0.5 \mathrm{~m}$. The indexes obtained by landscape types (Table 2) were: (1) the Patch Density (PD) Index, (2) the Landscape Shape Index (LSI), (3) Shannon's Diversity Index (SHDI) (Shannon and Weaver 1949), and (4) Simpson's Diversity Index (SIDI) (Simpson 1949). In addition, three mean canopy gap metrics with the level of significance were calculated for different landscape types: (1) area in hectares, (2) SHAPE Index, and (3) Euclidean nearest-neighbor distance (ENN).

The PD Index defines the number of canopy gaps per hectare, whereas the LSI is a simple measure for the aggregation by category:

$\mathrm{LSI}=\frac{e}{\min e}$,

where $e$ is the total length of an edge in terms of the number of cell surfaces including all boundary and background edge segments, and min $e$ is the minimum total length of a perimeter in terms of the number of cell surfaces. The LSI is 1 when the landscape consists of a single square and increases as the patch type becomes more disaggregated.

Both the SHDI and SIDI are commonly used measures of diversity in community ecology (e.g., Magurran 1988; Stiling 1996) and are determined as follows:

SHDI $=-\sum_{i=1}^{m}\left(P_{i} \ln P_{i}\right)$

and

$\mathrm{SIDI}=1-\sum_{i=1}^{m} P_{i}^{2}$

where $P_{i}$ is the proportion of the landscape occupied by the patch type $i$, i.e., the CG-class. Simpson's Index is less sensitive to the presence of rare types and has a more 


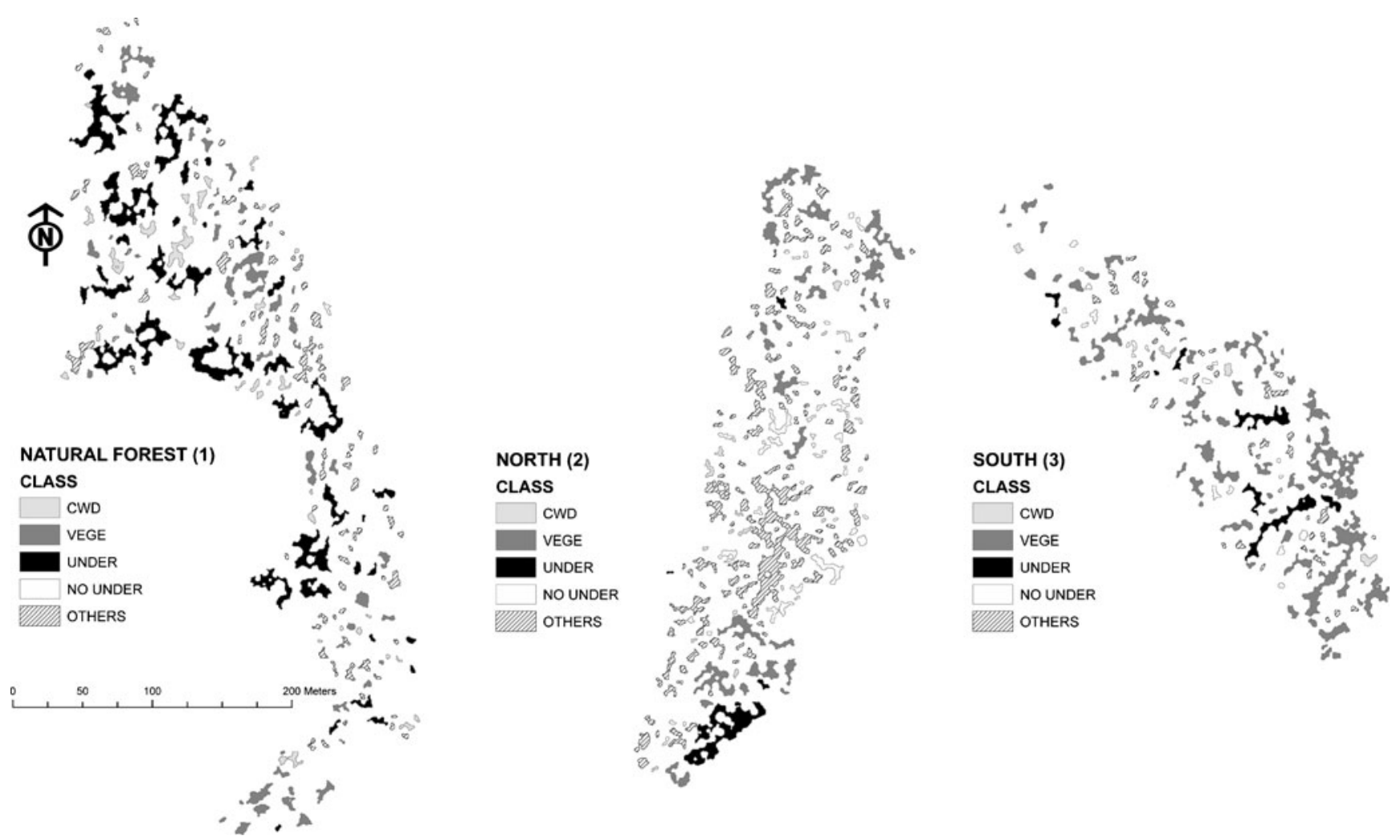

Fig. 2 Forest landscapes and classification of canopy gaps into the five types based on the field inventory: $D D W$ downed deadwood; $V E G E$ seedlings and vegetation; UNDER VEGE and DDW; NO_UNDER no seedlings, vegetation, or DDW; and OTHERS gaps with some DDW or seedlings

intuitive interpretation than the Shannon's Index. Specifically, the value of the Simpson's index represents the probability that any two randomly selected pixels represent different patch types. In addition, Stiling (1996) noted that the value of species diversity (SHDI) is often between 1.0 and 6.0, and the maximum diversity of a sample exists when all species areas are equally abundant.

The mean value of the SHAPE Index equals 1 when a patch is maximally compact (circle), and in the case of a

Table 2 Spatial characteristics which were calculated to landscape and CG-class levels with applicable statistical tests

\begin{tabular}{llll}
\hline & Landscape & CG-class & Test \\
\hline PD & $\times$ & $\times$ & \\
LSI & $\times$ & $\times$ & \\
SHDI & $\times$ & & \\
SIDI & $\times$ & & \\
AREA & $\times$ & $\times$ & $\times$ \\
SHAPE & $\times$ & $\times$ & $\times$ \\
ENN & $\times$ & $\times$ & $\times$ \\
PLAND & & $\times$ & \\
GSCI & & & \\
\hline
\end{tabular}

AREA is area in hectares raster format, the most compact form is a square with a value of 1.13 . The value of the index increases without limit as the patch shape becomes more irregular. The SHAPE Index for one patch is defined as follows:

$\mathrm{SHAPE}=\frac{p}{\min p}$,

where $p$ is the perimeter in terms of the number of cell surfaces and $\min p$ is the minimum perimeter in terms of the number of cell surfaces. The ENN distance (meter), which approaches 0 as the distance to the nearest neighbor decreases, is:

$\mathrm{ENN}=h$,

where $h$ is a planar ( $x / y$ direction) distance from a patch to the nearest neighboring patch of the same type (class), based on patch edge-to-edge distance, computed from cell center to cell center.

The same indexes were obtained also for the CGclasses, i.e., PD, LSI, AREA, SHAPE, and ENN (Table 2). In addition to the CG-classes, we calculated the percent of landscape values (PLAND), i.e., proportions of the landscape occupied by the five CG-classes and the mean values of the Gap Shape Complexity Index 
(GSCI) which bases on Patton's Diversity or Edge Index (Patton 1975):

$\mathrm{GSCI}=\frac{p}{2 \cdot \sqrt{a \cdot \pi}}$,

where $p$ is the perimeter and $a$ is the area of the patch. The mean values of the GSCI Index obtained for the circle shape and the square shape are 1.0 and 1.13 (indicates a relative complexity of $13 \%$ ), respectively.

The statistical tests applied to the mean values of the AREA, SHAPE, GSCI, and ENN metrics were the $t$ test and the analysis of variance. The $t$ test was used to determine whether the difference between the means of CG-classes obtained by landscape types of a given canopy metric or a given laser echo type was significant statistically or not. The analysis of variance, on the contrary, was applied when the significances of the differences between the indexes determined by the CG-classes were examined. However, the other density and diversity indexes were only obtainable for either landscape type or for the CG-class and, therefore, no statistical tests were applicable to them.

\subsection{Laser echo distribution metrics}

Canopy gaps were also analyzed by searching for the differences in the laser echo distributions in three predefined height classes based on the earlier ALS studies about canopy gaps and accuracy of the DTM: (1) less than $0.3 \mathrm{~m}$, (2) from 0.3 to $5 \mathrm{~m}$, and (3) more than $5 \mathrm{~m}$. The lowest limit was chosen because the accuracy of ALS data was known to be very high, having errors less than $0.3 \mathrm{~m}$ in DTM (Ahokas et al. 2003). The 5-m height threshold in canopy gap delineation has earlier been used by St-Onge and Vepakomma (2004) and Vepakomma et al. (2008), and therefore the second threshold of $5 \mathrm{~m}$ was chosen. Because of the interpolation method adopted, there were laser echoes at over $5 \mathrm{~m}$ aboveground level, which were, however, mainly found near the edges of the canopy gaps and were reflections from the branches of the edge trees. In some gaps, there were also some trees taller than $5 \mathrm{~m}$.

The echo types used in this study were: "first of many," "last of many," "only," and "all," i.e., all echoes combined. The height information was analyzed through the $z$ values of laser echoes, whereas the laser reflectance was detected through the intensity values. The intensity value is mainly based on the reflectivity and form of the surface but in the case the "last of many" echo, the intensity value also depends on earlier echoes. The mean canopy gaps of laser characteristics were grouped by the three height classes and the two landscape types or by the three height classes and the five CG-classes. The significances of the differences between the laser metrics were tested using the $t$ test and the analysis of variance.

\section{Results}

The value of the PD for the seminatural forest landscape was 35 gaps per hectare and for the managed forest landscape, 45 gaps per hectare. The values of the LSI for the same landscape types were 11.79 and 10.79, respectively.

The means of the AREA metrics for the natural forest landscape type and the managed forest landscape type were 46.5 and $39.0 \mathrm{~m}^{2}$, respectively. According to the $t$ test, the difference between the mean AREA metrics by the two landscape types is nonsignificant. In the seminatural forest landscape, the SHAPE Index was 1.62, the GSCI was 1.85, and the ENN was 9.74. In the managed forest landscape, the SHAPE Index was 1.59 , the GSCI was 1.82 , and the ENN was 8.47. In the case of the latter three metrics, the differences between the means of the CG-class metrics from the different landscapes were found to be nonsignificant according to the $t$ test.

The $t$ test assessment of the significances of the differences between the means of the two descriptive laser characteristics (mean height and mean intensity value) obtained for the four types of laser echoes for the two landscape types and the three predefined height classes is presented in Table 3. According to results shown in Table 3, the mean height of "all" laser echoes less than $0.3 \mathrm{~m}$ is higher in the seminatural forest landscape type than in the managed landscape type. A significant difference was also obtained for the "only" echoes where the mean height is higher in the seminatural forest landscape. In the second height class $(0.3-5 \mathrm{~m})$, the seminatural landscape had a mean height of approximately $0.5 \mathrm{~m}$ lower for "all" echo signals than the mean height of the "all" echoes of the managed landscape type. This is mainly due to large amounts of lower "only" echoes in the data from the seminatural landscape type. Also, the mean height of the "first of many" echoes was lower in the seminatural landscape type than in the managed landscape type. In the highest class $(>5 \mathrm{~m})$, the natural landscape type had a higher mean height of $0.8 \mathrm{~m}$ caused by the higher "first of many" echoes. However, the intensity values of the seminatural forest landscape type were lower in the lowest height class and higher in the two highest classes. The "first of many" echoes cannot exist for a height less than approximately $2.5 \mathrm{~m}$, and the number of "last of many" echoes for the two landscape types obtained for the class over $5 \mathrm{~m}$ were also low. Therefore, no statistics for the differences between the means of the laser characteristics were obtained for these two echo classes.

The PLAND, PD, and LSI metrics determined by the CG-classes indicated that in the classes DDW and UNDER, there were some differences between the seminatural and managed forest landscape type (Table 4). However, it was 
Table 3 Test results for differences in the means obtained between the landscape type determined for the laser metrics ( $z$ value and intensity) respective to the four laser echo types ("all," "first of many," "last of many," and "only") and collected by the predefined height classes $(<0.3$, $0.3-5$, and $>5 \mathrm{~m}$ )

${ }^{*} p<0.001$, the level of significance for the $t$ test

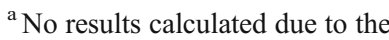
low number of observations

\begin{tabular}{|c|c|c|c|c|c|c|c|c|c|}
\hline & \multicolumn{2}{|l|}{$<0.3 \mathrm{~m}$} & & \multicolumn{2}{|c|}{$0.3-5 \mathrm{~m}$} & & \multicolumn{2}{|l|}{$>5 \mathrm{~m}$} & \\
\hline & Natural & Managed & & Natural & Managed & & Natural & Managed & \\
\hline \multicolumn{10}{|c|}{$z$ value } \\
\hline All & 0.088 & 0.084 & * & 1.645 & 2.129 & $*$ & 7.913 & 7.168 & * \\
\hline First & $-^{\mathrm{a}}$ & $-^{\mathrm{a}}$ & & 3.852 & 3.924 & $*$ & 8.437 & 7.300 & * \\
\hline Last & 0.093 & 0.093 & - & 0.998 & 0.857 & * & $-^{\mathrm{a}}$ & $-^{\mathrm{a}}$ & \\
\hline Only & 0.086 & 0.081 & * & 1.440 & 1.623 & $*$ & 6.431 & 6.701 & * \\
\hline \multicolumn{10}{|c|}{ Intensity } \\
\hline All & 73.132 & 74.621 & * & 62.975 & 53.818 & $*$ & 35.380 & 32.581 & * \\
\hline First & $--^{\mathrm{a}}$ & $-^{\mathrm{a}}$ & & 35.352 & 30.614 & $*$ & 28.514 & 26.608 & * \\
\hline Last & 38.179 & 40.031 & * & 35.008 & 35.672 & - & $-{ }^{\mathrm{a}}$ & $-{ }^{\mathrm{a}}$ & \\
\hline Only & 87.375 & 88.248 & * & 77.145 & 72.134 & $*$ & 59.785 & 57.052 & * \\
\hline
\end{tabular}

not possible to calculate statistical significance for these three indexes since the data comprised only three landscapes. The means for the area, shape, and isolation metrics for the five CG-classes are presented in Table 5. According to the results of the variance analysis and levels of significances to spatial metrics between CG-classes, the classes VEGE and UNDER have significant differences in AREA, GSCI, and SHAPE metrics, whereas the differences between the ENN metrics were nonsignificant.

The means of the two descriptive laser characteristics (mean height and mean intensity value) obtained for the four types of laser echoes by the five CG-classes in the three predefined height classes are presented in Table 6. The analysis of variance was applied for the variable height and intensity values for the four different fixed laser echo types (Table 7). There were significant differences between the CG-classes in all echo types and height classes except in the intensity values of the "last of many" echoes in $0.3-$ 5-m height class, where calculated statistical significance $(F)$ was $1.74(p=0.137)$ (Table 7$)$. In $z$ values, there were significant differences in $76 \%$ of the cases between the CGclasses for all echo types and height classes. With the intensity value, significant differences existed in $64 \%$ of the connections. When analyzing the $z$ values between the CGclasses, most of the significant connections were detected for the echo types "all" and "only" in the height class $0.3-$ $5 \mathrm{~m}$ in and for the echo type of "all" in the height class over $5 \mathrm{~m}$ (Table 7). For the intensity value, the corresponding height class was under $0.3 \mathrm{~m}$ with "only" echoes. In Table 7 are the classes where there exist significant differences according to the analysis of variance in the CG-classes and laser metrics in different height classes and echo types. The class UNDER has ten different metrics where differences can be found, VEGE has eight, NO_UNDER and OTHERS have seven metrics each (Table 7). "All” echoes in 0.3-5-m height class and "only" echoes in under 0.3-m height class
Table 4 Density and edge metrics obtained by landscape types and the five predefined canopy gap character classes

\begin{tabular}{llllll}
\hline & DDW & VEGE & UNDER & NO_UNDER & OTHERS \\
\hline PLAND & & & & & \\
Natural & 1.44 & 3.15 & 8.87 & 0.03 & 2.79 \\
Managed & 0.44 & 8.24 & 2.24 & 1.38 & 5.45 \\
Managed N & 0.38 & 4.82 & 1.77 & 1.93 & 8.81 \\
Managed S & 0.50 & 11.65 & 2.70 & 0.82 & 2.08 \\
PD & & & & & 15.43 \\
Natural & 5.73 & 7.32 & 6.36 & 0.16 & 20.88 \\
Managed & 2.11 & 13.08 & 1.61 & 7.45 & 28.33 \\
Managed N & 2.73 & 5.88 & 0.84 & 9.23 & 13.43 \\
Managed S & 1.49 & 20.29 & 2.39 & 5.67 & 13.83 \\
LSI & & & & & 13.50 \\
Natural & 9.08 & 10.80 & 14.27 & 1.79 & 17.65 \\
Managed & 4.29 & 12.78 & 5.59 & 7.95 & 9.35 \\
Managed N & 5.15 & 10.79 & 4.77 & 10.21 & 5.69 \\
Managed S & 3.42 & 14.77 & 6.40 & & \\
\hline
\end{tabular}


Table 5 Means for area, shape, and isolation metrics in five predefined canopy gap character classes

\begin{tabular}{lllll}
\hline & AREA & GSCI & SHAPE & ENN \\
\hline DDW & 23.19 & 1.73 & 1.52 & 22.84 \\
VEGE & $57.63^{\mathrm{a}}$ & $1.99^{\mathrm{a}}$ & $1.75^{\mathrm{a}}$ & 7.47 \\
UNDER & $140.78^{\mathrm{a}}$ & $2.44^{\mathrm{a}}$ & $2.16^{\mathrm{a}}$ & 15.41 \\
NO_UNDER & 19.02 & 1.68 & 1.47 & 7.87 \\
OTHERS & 24.00 & 1.69 & 1.47 & 6.02
\end{tabular}

$D D W$ gaps with downed deadwood, $V E G E$ gaps with different vegetation, UNDER gaps with DDW and VEGE, NO_UNDER gaps with no DDW and VEGE, OTHERS gaps with small amounts of DDW or some seedlings found in field inventory

${ }^{a}$ Values which differ significantly from the others according to the analysis of variance

have seven different metrics where significant differences can be identified (Table 7).

\section{Discussion}

The earlier studies concerning canopy gaps (e.g., Kuuluvainen 1994; McCarthy 2001) have mainly focused on the general development processes of the gaps. The delineation of canopy gaps has been difficult to implement and, therefore, only study designs operating at small spatial scales have been adopted. Laser scanning data provide new possibilities to study forest canopy gaps over large forest areas, and in addition, the 3D information produced by the laser scanner also makes it possible to delineate individual canopy gaps in boreal forests.

This study used ALS data to identify the differences between canopy gaps in seminatural and managed forests. The automated canopy gap delineation was implemented by using a threshold of a certain height (e.g., Koukoulas and Blackburn 2005). After the delineation, laser echo distributions by canopy gaps were analyzed. Results indicate that canopy gaps with dense undergrowths (VEGE and UNDER) can be identified from the other CG-classes by spatial metrics (see Table 5) and laser echo heights (see Tables 6 and 7), which support the findings by Vehmas et al. (2009b). Several landscape metrics were also used to analyze differences between seminatural and managed landscapes and canopy gap types. All the landscapes were wall-to-wall mapped, and all the canopy gaps were fieldvisited and existence-verified. Therefore, ALS data were deemed to provide trustworthy material for the analysis of canopy gaps. However, the accuracy of the exact gap drip line delineation by measuring borderlines, for example, was not assessed.

Among the calculated spatial metrics, we did not find any differences in area, shape, or isolation metrics between

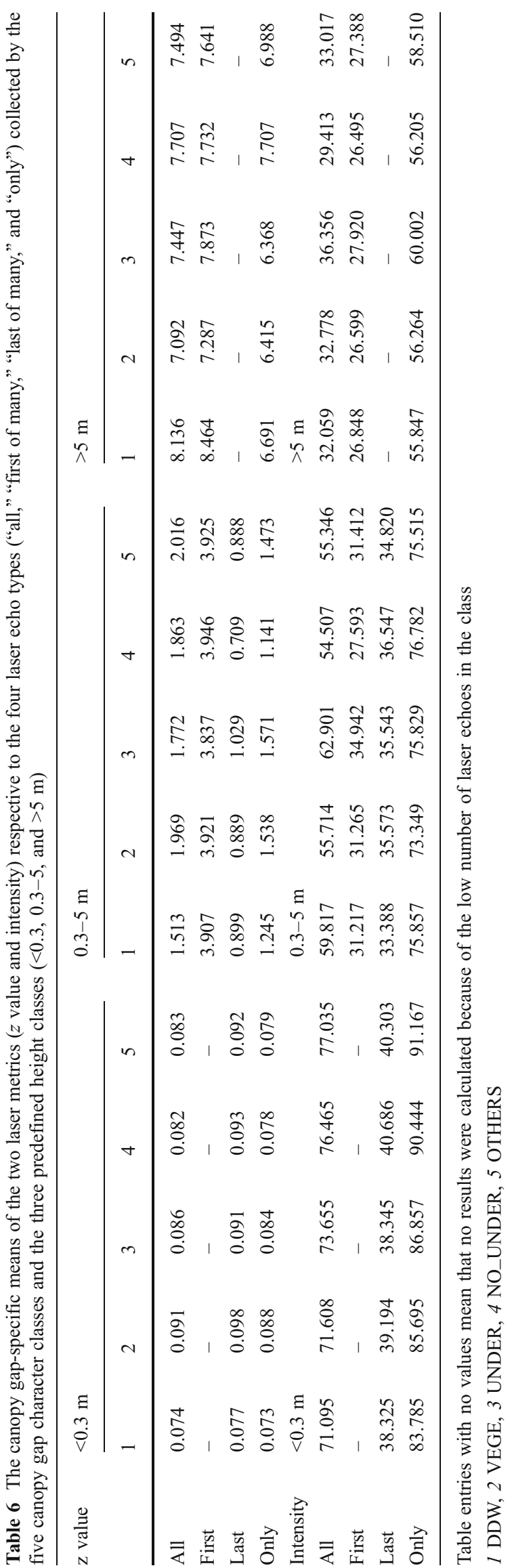


Table 7 Existing significant differences between single canopy gap character class to all other four classes in laser metrics of $z$ value $(z)$ and intensity value $(i)$ in different predefined height classes $(<0.3,0.3-5$, and $>5 \mathrm{~m}$ ) and laser echo types ( $A=$ =all," $F=$ "first of many," $L=$ "last of many," and $O=$ "only" echoes)

\begin{tabular}{|c|c|c|c|c|c|c|c|c|c|c|c|c|}
\hline & \multicolumn{4}{|c|}{$<0.3 \mathrm{~m}$} & \multicolumn{4}{|c|}{$0.3-5 \mathrm{~m}$} & \multicolumn{4}{|c|}{$>5 \mathrm{~m}$} \\
\hline & $A$ & $F$ & $L$ & $O$ & $A$ & $F$ & $L$ & $O$ & $A$ & $F$ & $L$ & $O$ \\
\hline DDW & $z$ & & $z$ & $i$ & $z i$ & & & & $z$ & $z$ & & \\
\hline VEGE & $z$ & & & $z i$ & $z$ & & & $z i$ & $z$ & $z$ & & \\
\hline UNDER & $i$ & & & $z i$ & $z i$ & $i$ & $z$ & $z$ & $i$ & & & $i$ \\
\hline NO_UNDER & & & & $\mathrm{i}$ & $z$ & $i$ & $z$ & & $z i$ & & & $z$ \\
\hline OTHERS & & & & $i$ & $z$ & & & $z$ & & & & \\
\hline
\end{tabular}

The calculated significance level of variance analysis is $p<0.05$

the seminatural and managed forests. The values of the Patton's GSCI Index obtained for the two forest landscape types were almost equal, i.e., 1.82 and 1.85. The highest GSCI values for the seminatural forest and the managed forest were 4.81 and 5.46, respectively, indicating a high complexity of canopy gaps. Koukoulas and Blackburn (2005) investigated broadleaved deciduous woodland characteristics and obtained a value of 2.64 for the GSCI Index in the most complex canopy gap. We calculated also commonly used SIDI and SHDI. There were no differences in SIDI values between landscapes. The SIDI Indexes were over 0.6 for both forest types, which indicate a relatively high diversity ( 0 means no diversity and 1 indicates infinite diversity). Also, SHDI values were rather similar in the landscapes, varying from 1.16 to 1.26 . In general, the spatial canopy gap metrics did not give any evidence to distinguish canopy gaps of the seminatural forest from those of the managed forest. Both the canopy gap diversity and the variation between single canopy gaps were high, but at the landscape level, there were no statistical differences assessed with the $t$ test.

In earlier studies (e.g., Bollandsås et al. 2008; Maltamo et al. 2005), the hits below $0.3-0.5 \mathrm{~m}$ have usually been classified as ground echoes, whereas in this study, different laser echo characteristics below $0.3 \mathrm{~m}$ were also analyzed. Based on the field visits, the 5-m height threshold seems appropriate for the delineation of canopy gaps for the mature boreal forest stands used in this study. However, if there had been higher variations in the vertical structure, then the 5-m threshold would not have worked so well. We also found that there were no "first of many" echoes in the lowest height class, and the amount of the "only" echoes was low in the over 5-m height class (Table 3). Therefore, these classes were excluded from the analysis.

To analyze the canopy gap laser data between landscape types in three different height classes, we used the mean $z$ values (height) and intensity values showing statistically significant differences (Table 3 ). There are clear differences between the canopy gaps of seminatural and managed forests in terms of laser echo mean heights. Results indicate that laser echo responses are slightly higher in the lowest height class of the seminatural forest or there is more uncertainty in the DTM which may be resulting from dense undergrowths or high amounts of downed deadwood. In the highest height class, the "first of many" echo mean height is higher in the case of the seminatural forest which, together with the lower "only" echoes, indicates that there are more variations in the vertical vegetation layers when compared to the managed forest.

We also calculated the intensity values for the same height classes in the seminatural and managed forests and noticed that the intensity values increased if the laser echoes were from the lower height classes. In the natural forest, the intensity value was higher in the two highest classes indicating a stronger vegetation response in the seminatural forest. It was also observed that in the seminatural forest, the "first of many" and "last of many" echoes in the $0.3-5-\mathrm{m}$ height class had almost the same intensity.

Differences in spatial metrics obtained for the CGclasses were also detectable at least to a certain extent. Classes with seedlings or lesser vegetation and deadwood (VEGE and UNDER) were separated from other groups by the characteristics GSCI, AREA, and SHAPE (Tables 4 and 5). The result shows that canopy gaps with dense undergrowth are larger than the other groups, which might indicate better regeneration and growing possibilities in larger and more complex canopy gaps because of better light conditions. Both the shape metric and the Patton's GSCI are also higher in the class UNDER when compared to other groups. We also found differences in CG-classes between the seminatural and managed forests. In the seminatural forest, there existed more canopy gaps in the classes DDW and UNDER, and LSI is also higher in these classes. In the dataset from the seminatural forest, there was only one canopy gap in the class NO_UNDER which might 
indicate more vegetation or existence of deadwood in the canopy gaps when compared to the managed forests where the count for this class was 63 gaps. These results indicate that in managed forests, the wood is transported away and no large diameter downed deadwood can be found on the ground. Additionally, in the managed spruce-dominated forests, the seedlings of fast growing trees are rare, and therefore, less vegetation is detected in the canopy gaps within managed forests. However, further studies on the specification of canopy gap types and level of naturalness of forests are required to confirm these observations.

According to the analysis of variance, class-specific results in predefined height classes from the different laser echoes show some differences between canopy gap classes (Tables 6 and 7). The CG-class UNDER had ten different metrics to separate it from other classes, whereas in the other character classes, the number of metrics varied from three to eight. As a result, UNDER class can be separated from other classes more easily because of differences in the vertical laser echo distributions. Differences are caused by the lowest $z$ values of the "first of many" echoes (Table 6), which is assumed to indicate good light conditions favoring the undergrowth inside the canopy gaps, despite the fact that growth possibilities are reduced by large pieces of fallen deadwood. In the class UNDER, the mean heights of the echoes in managed forests also correspond to those of the seminatural forest (Tables 3 and 6). For the height class of $0.3-5 \mathrm{~m}$, the echo class "all" was the most suitable for detecting differences in $z$ values between CG-classes. There are also differences between canopy gap types when analyzing intensity values. In the height class of under $0.3 \mathrm{~m}$ the "only" echoes have different intensities in each CG-class. Generally, the intensity is higher at lower heights, and in this case, the intensity values vary because of the differences in contents of the canopy gaps. The delineation methodology, with the threshold of $5 \mathrm{~m}$ used in this study may inflict error in the spatial metrics, but based on the field visits, the error seems to be minor and does not affect to the analysis of the results. An alternative method would be to use a variable height threshold based on the ALS data. Additionally, the minimum gap size and created gap map from CHM with pixel size of $0.5 \mathrm{~m}$ seemed to work well. However, various gap sizes and gap delineation methods need to be studied further to verify the results found in this study. The interpretation behind the CG-class differences remain, however, unknown and therefore more research is needed to explain the findings of this study.

\section{Conclusions}

This study utilized wall-to-wall ALS data to detect differences between canopy gaps of seminatural and managed forests. The analysis was based on the variation in point distributions of the different laser echo types making it possible to take a closer look at the canopy gap characteristics. According to the results, canopy gaps in the seminatural forest can be separated from those of the managed forest by analyzing vertical differences in laser echo distributions. We also used some ALS identified canopy gap characteristics, such as dense undergrowth and downed deadwood, to separate seminatural forest canopy gaps from managed ones. In further studies, more landscape units should be included to justify that different canopy gap types are also separable and identifiable at landscape level. The new approach and methodology developed in this study could potentially be used to evaluate the naturalness and successional stage of closed canopy boreal forests. In addition, the methods used in this study might be applicable to other forested areas and different vegetation zones because of the ability of ALS data to characterize differences in the vertical structure of the vegetation cover.

Acknowledgments This research was conducted in the University of Eastern Finland, and the Joensuu Research Unit of the Finnish Forest Research Institute. It was mainly funded by the Maj and Tor Nessling Foundation and partly supported by the strategic funding of the University of Eastern Finland. We are grateful to these institutions for the resources and funding.

\section{References}

Ackermann F (1999) Airborne laser scanning — present status and future expectations. ISPRS J Photogramm Remote Sens 54:64-67

Ahokas E, Kaartinen H, Yu X, Hyyppä J, Hyyppä H (2003) Analyzing the effects related to the accuracy of laser scanning for digital elevation and target models. Proceedings of the 22nd Symposium of the European Association of Remote Sensing Laboratories: In Geoinformation for European wide Integration, 4-6 June 2002, Prague, pp. 13-18

Axelsson P (2000) DEM generation from laser scanner data using TIN models. The International Archives of the Photogrammetry and Remote Sensing 33:110-117

Bollandsås OM, Hanssen KH, Marthiniussen S, Næsset E (2008) Measures of spatial forest structure derived from airborne laser data are associated with natural regeneration patterns in an uneven-aged spruce forest. For Ecol Manag 255:953-961

Gaulton R, Malthus TJ (2010) LiDAR mapping of canopy gaps in continuous cover forests; a comparison of canopy height model and point cloud based techniques. Int J Remote Sens 31:1193-1211

Hirata Y, Tanaka H, Furuya N (2008) Canopy and gap dynamics analysed using multi-temporal airborne laser scanner data in a temperate deciduous forest. In: Hill R, Rosette J, Suarez J (eds) Proceedings of Silvilaser 2008, 8th International Conference On Lidar Applications In Forest Assessment and Inventory, Edinburgh, Sept 2008, SilviLaser 2008 Organizing Committee, Bournemouth, pp $144-150$

Kalliola R (1973) Suomen kasvimaantiede. WSOY, Porvoo, p. 308 (in Finnish)

Koukoulas S, Blackburn GA (2004) Quantifying the spatial properties of forest canopy gaps using Lidar imagery and GIS. Int J Remote Sens 25:3049-3071 
Koukoulas S, Blackburn GA (2005) Spatial relationships between tree species and gap characteristics in broad-leaved deciduous woodland. J Veg Sci 16:587-596

Kuuluvainen T (1994) Gap disturbance, ground microtopography, and the regeneration dynamics of boreal coniferous forests in Finland: a review. Ann Zoo Fenn 31:35-51

Liu Q, Hytteborn H (1991) Gap structure, disturbance and regeneration in a primeval Picea abies forest. J Veg Sci 2:391-402

Lyytikäinen A (1991) Kolin luonto, maisema ja kulttuurihistoria. Kolin luonnonsuojelututkimukset. Vesi- ja ympäristöhallituksen monistesarja 308. (in Finnish)

Magurran AE (1988) Ecological diversity and its management. Princeton University Press, Princeton, p 179

Maltamo M, Packalén P, Yu X, Eerikäinen K, Hyyppä J, Pitkänen J (2005) Identifying and quantifying structural characteristics of heterogenous boreal forests using laser scanner data. For Ecol Manag 216:41-50

McCarthy J (2001) Gap dynamics of forest trees: a review with particular attention to boreal forests. Environ Rev 9:1-59

McGarigal K, Cushman SA, Neel MC, Ene E (2002) FRAGSTATS: Spatial Pattern Analysis Program for Categorical Maps. Computer software program produced by the authors at the University of Massachusetts, Amherst. www.umass.edu/landeco/research/ fragstats/fragstats.html Accessed 26 Feb 2010

Patton DR (1975) A diversity index for quatifying habitat 'edge'. Wildl Soc Bull 3:171-173

Pesonen A, Maltamo M, Eerikäinen K, Packalén P (2008) Airborne laser scanning-based prediction of coarse woody debris volumes in a conservation area. For Ecol Manag 255:3288-3296

Rouvinen S, Kouki J (2008) The natural Northern European boreal forests: unifying the concepts, terminologies, and their application. Sil Fenn 42:135-146
Shannon C, Weaver W (1949) The mathematical theory of communication. Univ. Illinois Press, Urbana, p 117

Siitonen J, Martikainen P, Punttila P, Rauh J (2000) Coarse woody debris and stand characteristics in mature managed and oldgrowth boreal mesic forests in southern Finland. For Ecol Manag 128:211-225

Simpson EH (1949) Measurement of diversity. Nature 163:688

Stiling PB (1996) Ecology: theories and applications, 2nd edn. Prentice Hall International Editions, New Jersey, p 539

St-Onge B, Vepakomma U (2004) Assessing forest gap dynamics and growth using multi-temporal laser-scanner data. In Proc. of Laser-Scanners for Forest and Landscape AssessmentsInstruments, Processing Methods and Applications International Conference, Freiburg im Breisgau, 3-6 October 2004, pp $173-178$

Vehmas M, Kouki J, Eerikäinen K (2009a) Long-term spatio-temporal dynamics and historical continuity of European aspen (Populus tremula L.) stands in the Koli National Park, eastern Finland. Forestry 82:135-148

Vehmas M, Packalén P, Maltamo M, (2009b) Assessing deadwood existence in canopy gaps by using ALS data. Conference Proceedings, SilviLaser 2009, October 14-16, College Station, Texas USA, pp 137-144

Vepakomma U, St-Onge B, Kneeshaw D (2008) Spatially explicit characterization of boreal forest gap dynamics using multitemporal lidar data. Rem Sens Environ 112:2326-2340

Zhang K (2008) Identification of gaps in mangrove forests with airborne LIDAR. Rem Sens Environ 112:2309-2325

Zhu J, Matsuzaki T, Lee F, Gonda Y (2003) Effect of gap size created by thinning on seedling emergency, survival and establishment in a costal pine forest. For Ecol Manag 182:339-354 